\title{
Isolation and identification of Concanavalin A binding glycoproteins from human seminal plasma: A step towards identification of male infertility marker proteins
}

\author{
Anil Kumar Tomar ${ }^{\mathrm{a}}$, Balwinder Singh Sooch ${ }^{\mathrm{b}}$, Isha Raj ${ }^{\mathrm{c}}$, Sarman Singh ${ }^{\mathrm{d}}$, Tej P. Singh ${ }^{\mathrm{a}}$ and \\ Savita Yadav ${ }^{\mathrm{a}, *}$ \\ ${ }^{a}$ Department of Biophysics, All India Institute of Medical Sciences, New Delhi, India \\ ${ }^{\mathrm{b}}$ Department of Biotechnology, Punjabi University, Patiala, India \\ ${ }^{\mathrm{c}}$ School of Life Sciences, Jawaharlal Nehru University, New Delhi, India \\ ${ }^{\mathrm{d}}$ Department of Laboratory Medicine, All India Institute of Medical Sciences, New Delhi, India
}

\begin{abstract}
Human seminal plasma contains a large array of proteins of clinical importance which are essentially needed to maintain the reproductive physiology of spermatozoa and for successful fertilization. Thus, isolation and identification of seminal plasma proteins is of paramount significance for their biophysical characterization and functional analysis in reproductive physiological processes. In this study, we have isolated Concanavalin-A binding glycoproteins from human seminal plasma and subsequently identified them by MALDI-TOF/MS analysis. The major proteins, as identified in this study, are Aminopeptidase N, lactoferrin, prostatic acid phosphatase, zinc-alpha-2-glycoprotein, prostate specific antigen, progestagen-associated endometrial protein, Izumo sperm-egg fusion protein and prolactin inducible protein. This paper also reports preliminary studies to identify altered expression of these proteins in oligospermia and azoospermia in comparison to normospermia. In oligospermia, five proteins were found to be downregulated while in azoospermia, four proteins were downregulated and two proteins were upregulated. Thus, this study is of immense biomedical interest towards identification of potential male infertility marker proteins in seminal plasma.
\end{abstract}

Keywords: Azoospermia, glycoproteins, lectin affinity chromatography, male infertility, oligospermia

Abbreviations
$\begin{array}{ll}\text { APN } & \text { Aminopeptidase N precursor; } \\ \text { Con A } & \text { Concanavalin A; } \\ \text { GCDFP-15 } & \text { Gross cystic disease fluid protein 15; } \\ \text { hZAG } & \text { Human zinc-alpha-2-glycoprotein; } \\ \text { Izumo } & \text { Izumo sperm-egg fusion protein 1; } \\ \text { LF } & \text { Lactoferrin; } \\ \text { MALDI-TOF } & \text { Matrix associated laser desorption ionization-time } \\ & \text { of flight; }\end{array}$

${ }^{*}$ Corresponding author: Savita Yadav, Additional Professor, Department of Biophysics, All India Institute of Medical sciences, New Delhi 110029, India. E-mail: savita11@gmail.com.

\author{
PAEP Progestagen-associated endometrial protein; \\ PAP Prostatic acid phosphatase; \\ PAS staining Periodic acid-Schiff staining; \\ PIP Prolactin inducible protein; \\ PSA Prostate specific antigen; \\ SABP Secretory actin-binding protein; \\ SDS-PAGE Sodium dodecyl sulphate-polyacrylamide gel elec- \\ trophoresis
}

\section{Introduction}

Almost $40 \%$ cases of infertility are due to the male factors. The main factors, responsible for male infertility, include lack of sperms (azoospermia), poor sperm quantity (oligospermia), low sperm motility (asthenozoospermia), high percentage of abnormal sperms (ter- 
atozoospermia) and biologically dysfunctional sperms lacking fertilizing capacity. Clinical fertility tests are based on the detailed analysis of various sperm factors including concentration, motility, morphology etc. Turek [1] has reported that even after the complete assessment of all the factors, $30-50 \%$ cases of infertility have no known causes. Thus, there is an indispensable need for sensitive diagnostic targets for infertility.

We know that seminal fluid serves as a vehicle for ejaculated sperm to the female genital tract. It exerts several effects on sperm function and on the female genital tract that lead to the fertilization [2]. Human seminal plasma contains a large array of proteins of clinical importance. These proteins are essentially needed to maintain the reproductive physiology of spermatozoa and for successful fertilization. So, the characterization of the proteins of seminal plasma is of paramount significance. The protein concentration in human seminal plasma is about $35-55 \mathrm{mg} / \mathrm{mL}$, which makes it a rich and easily accessible source for protein identification. Pilch and Mann [3] have done large scale proteomic analysis and identified 923 proteins in the human seminal plasma. Many attempts have been made to identify the constituents of seminal plasma; however, there have been very few studies designed to identify diseaserelated markers in seminal plasma, particularly those related to male infertility. To identify male infertility markers, it is important to examine and identify differentially expressed proteins in seminal plasma samples from fertile and non-fertile men.

From a medical perspective, many attempts have been made to identify male infertility marker proteins. Most of the studies have focused the changes in proteomic profile of sperm during various functional modifications (i.e. during epididymal transit, capacitaion). The significant contributions are by Zhao et al. [4], Martínez-Heredia et al. [5], Liao et al. [6], Secciani et al. [7], Siva et al. [8] and Baker et al. [9]. Only few studies have focused seminal plasma as a potential source for identification of male infertility marker proteins. The major attempt in this direction was made by Yamakawa et al. [10]. In their study, they have done comparative analysis of interindividual variations in the seminal plasma proteome of fertile men with identification of potential markers for azoospermia in infertile patients. In a recent study, Bai et al. [11] have identified differentially expressed proteins in the seminal plasma of healthy fertile and non-obstructive azoospermia men by shotgun proteomic strategy.

The studies related to expression of proteins, their functions and interactions are essential for understand- ing the various disease mechanisms. The developments in the field of clinical proteomics have extensively facilitated the systematic identification of proteins of clinical importance including biomarker discovery. The discovery of proteins with post-translational modifications has become an important frontier of proteomics studies. Glycosylation, one of the most common posttranslational modifications, plays essential roles in controlling various biological processes in immunology, cancer, protein folding, host - pathogen interactions, human diseases and signal transduction etc. In recent times, it has become an imperative target for proteomic research and has great potential for clinical applications. Comparative glycoproteomics is also emerged as a powerful tool in a wide variety of research, including biomarker discovery, disease diagnosis and glycosylation profiling [12]. Lectin affinity chromatography allows the isolation and enrichment of glycoproteins and glycopeptides. Concanavalin A (Con A) is a common lectin isolated from the jack bean, which has broad specificity, to isolate glycoproteins rather than some specific structural types [13]. Many of the previous studies have successfully applied Con A lectin affinity chromatography to enrich and isolate glycoproteins [14-17]. More captivatingly, Con A-interacting fraction of human seminal plasma shows decapacitating activity [18]. Thus, the study towards isolation and identification of various proteins of this fraction is of vast importance and may help us in better understanding of fertility related processes.

The main objective of this study was to isolate Concanavalin-A binding glycoproteins from human seminal plasma using affinity chromatography and subsequently to identify them. In the next step, we have also done preliminary studies to analyse the differential expression profile of these proteins in oligospermia and azoospermia in comparison to normospermia.

\section{Methodology}

\subsection{Sample collection and preparation}

Human semen samples (normospermic, oligospermic and azoospermic) were collected from Department of Laboratory Medicine, All India Institute of Medical Sciences, India. The samples were collected from those patients only who were visiting to Infertility Clinic and have been tested normal, Oligospermic or azoospermic. The World Health Organization (WHO) recommendations were followed to categories 
different types of samples. The HIV positive samples and/or those contaminated with blood were excluded from this study. The samples included in this study were selected using the following criteria-age group of donors -20 to 40 years, normospermia (sperm count $>$ 50 million/mL, sperm motility $>60 \%$ ), oligospermia ( sperm count $<10$ million/mL, sperm motility $>60 \%$ ) and non-obstructive azoospermia (no sperms, fructose $+v e$ ). The samples were centrifuged at 10,000 $\mathrm{g}$ for 30 minutes at $4^{\circ} \mathrm{C}$ to remove spermatozoa. The supernatants obtained were pooled and stored at $-20^{\circ} \mathrm{C}$. The protein concentration measured in these samples was $51.34 \mathrm{mg} / \mathrm{mL}, 45.99 \mathrm{mg} / \mathrm{mL}$ and $57.80 \mathrm{mg} / \mathrm{mL}$ in normospermia, oligospermia and azoospermia respectively.

\subsection{Lectin affinity chromatography: Isolation of Concanavalin-A binding glycoproteins from normal seminal plasma}

Ten millilitre Con A-agarose affinity resin (SigmaAldrich, Inc.) was used for protein isolation. The column was prewashed with five column volumes $(5 \times$ $10 \mathrm{~mL})$ of wash solution $\left(1 \mathrm{M} \mathrm{NaCl}, 5 \mathrm{mM} \mathrm{MgCl}_{2}\right.$, $5 \mathrm{mM} \mathrm{MnCl}_{2}$, and $5 \mathrm{mM} \mathrm{CaCl}_{2}$ ) according to manufacturer's recommendations and equilibrated with phosphate buffer saline (PBS: $50 \mathrm{mM}$ phosphate buffer, $\mathrm{pH} 7,200 \mathrm{mM} \mathrm{NaCl}$ ). PBS was used as equilibration/binding buffer. Ten millilitre seminal plasma, diluted 1:4 with PBS, was applied to the column. Non-adsorbed proteins were washed out with PBS and bound proteins were eluted with $0.5 \mathrm{M}$ Methyl- $\alpha-\mathrm{D}$ Mannopyranoside. The fraction of bound proteins was concentrated and desalted using ultrafiltration (Millipore, Billerica, MA) and lyophilized.

\subsection{Comparative expression analysis in normospermia, oligospermia and azoospermia}

For comparative expression analysis, Con A binding proteins from normospermic, oligospermic and azoospermic seminal plasma samples $(n=25$ for each type of sample) were isolated by Nanosep ${ }^{\circledR}$ spin devices (Pall Corporation). The different types of samples were pooled separately after centrifugation. Twenty five $\mu \mathrm{L}$ resin was pipetted into three NanoSep spin devices. The resin was prewashed with $125 \mu \mathrm{L}$ of wash solution. Centrifugation at $2000 \mathrm{~g}$ for 2 minutes at $4{ }^{\circ} \mathrm{C}$ was used for removal of excess liquid and fraction collection. $250 \mu \mathrm{L}$ equilibration buffer (PBS) was added and incubated for 10 minutes. Excess liquid was re- moved after incubation and $25 \mu \mathrm{L}$ sample was added to the resin. Samples were thoroughly mixed (on a rotary mixer) for 30 minutes at room temperature to facilitate binding of proteins to the resin. The resin was washed with $500 \mu \mathrm{L}$ equilibration buffer. Retained proteins were eluted with $100 \mu \mathrm{L}$ of $0.5 \mathrm{M}$ Methyl$\alpha$-D-Mannopyranoside. The fractions of bound proteins from normospermic, oligospermic and azoospermic seminal plasma were collected separately and analysed by gel electrophoresis.

\subsection{Gel electrophoresis}

SDS-PAGE was carried out using $12 \%$ polyacrylamide gel under reducing conditions as previously described [19]. Fifty microgram protein was loaded in each well. Proteins on gel were visualized by Coomassie Brilliant Blue G-250 as well as by PAS staining. In another set up, eluted protein fraction was acetone precipitated (sample and acetone ratio was 1:4) prior to SDS-PAGE analysis. Acetone precipitation is routine procedure to remove the interfering compounds such as ionic detergents from the protein samples.

\subsection{In-gel digestion and MALDI-TOF analysis}

The protein bands were manually excised from Coomassie stained polyacrylamide gel. To remove the dye, the bands were washed thrice with $\mathrm{ACN}: \mathrm{H}_{2} \mathrm{O}$ (50\%, v/v) containing $25 \mathrm{mM}$ Ammonium bicarbonate. The in-gel digestion using Trypsin was carried out as previously described [20]. The reconstituted in-gel digested sample $(4 \mu \mathrm{L})$ was mixed with $1 \mathrm{ml}$ of matrix solution in $50 \%$ ACN and $0.1 \%$ TFA and spotted on to a MALDI target plate. MALDI-TOF MS analysis was performed using Bruker Autoflex MALDI-TOF mass spectrometer (Bruker Daltonik, Bremen, Germany). Peptides from mass spectra of in-gel digested samples were matched against protein databases such as NCBInr and MSDB using Mascot search engine (Matrix Sciences, London, UK) for peptide-mass-fingerprinting.

\section{Results}

Con A binding proteins were eluted with Methyl$\alpha$-D-Mannopyranoside. Average protein yield (Con A binding fraction) was $3.1 \mathrm{mg} / \mathrm{mL}$. The eluate was desalted, lyophilized and analysed on $12 \%$ SDS-PAGE. More than ten protein bands were resolved on the gel, as visualized by Coomassie Brilliant Blue staining 
Table 1

Identification of major Concanavalin A binding proteins of human seminal plasma

\begin{tabular}{|c|c|c|c|c|c|}
\hline Protein name & Accession number & Number of peptides & $\%$ sequence coverage & Mowse score & Database search \\
\hline Aminopeptidase $\mathrm{N}$ precursor & P15144 & 10 & 20.0 & 70.4 & NCBInr \\
\hline Lactoferrin & P02788 & 19 & 36.0 & 173.0 & NCBInr \\
\hline Lactoferrin isoform 1 & P02788 & 19 & 32.1 & 136.0 & NCBInr \\
\hline Prostatic acid phosphatase & P15309 & 13 & 43.8 & 129.0 & NCBInr \\
\hline Human Zinc-Alpha-2-Glycoprotein & $\mathrm{P} 25311$ & 13 & 54.4 & 124.0 & NCBInr \\
\hline Prostate specific antigen & P07288 & 6 & 63.5 & 85.1 & NCBInr \\
\hline Progestagen-associated endometrial protein & Q5T6T6 & 6 & 52.3 & 63.7 & MSDB \\
\hline Kinesin light chain 4 & Q9NSK0 & 6 & 18.5 & 55.9 & MSDB \\
\hline Izumo sperm-egg fusion protein 1 & Q8IYV9 & 4 & 24.5 & 75.5 & NCBInr \\
\hline Prolactin inducible protein & P12273 & 11 & 71.9 & 142.0 & NCBInr \\
\hline
\end{tabular}

$\mathbf{A}$

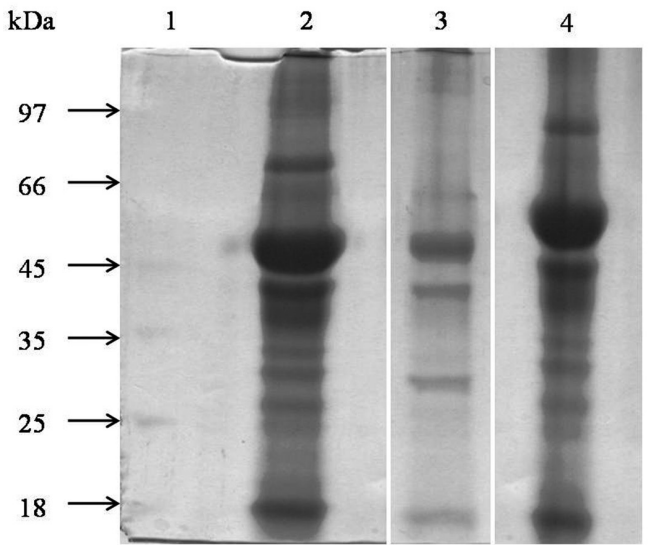

B

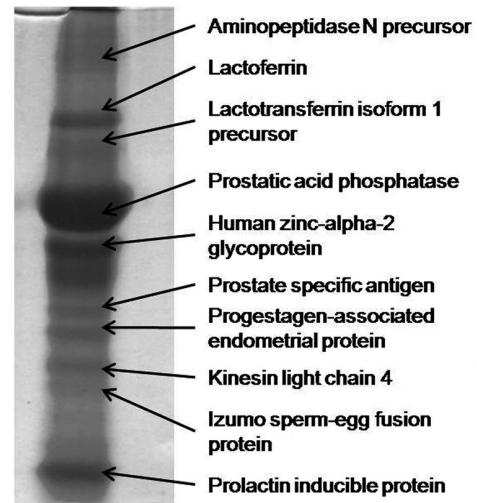

Fig. 1. Identification of Concanavalin A binding proteins from human seminal plasma. (A) $12 \%$ SDS-PAGE profile Lanes 1-3: Coomassie staining (Lane 1: Molecular weight markers; Lane 2: without acetone precipitation; Lane 3: after acetone precipitation); Lane 4: PAS staining (B) Proteins identified by MALDI-TOF/MS analysis: (from up to down) Aminopeptidase N precursor, lactoferrin, lactoferrin isoform 1, prostatic acid phosphatase, human zinc-alpha-2-glycoprotein, prostate specific antigen, progestagen-associated endometrial protein, kinesin light chain 4, izumo sperm-egg fusion protein 1 and prolactin inducible protein.

(Fig. 1A, Lane 2) and PAS staining (Fig. 1A, Lane 4). When eluate was analysed after treating with $80 \%$ acetone, some protein bands were missing on SDS-PAGE gel, indicating that acetone did not precipitate all the proteins of the fraction (Fig. 1A, Lane 3). The protein bands were manually excised from gel and in-gel digested using trypsin followed by MALDI-TOF mass spectrometry analysis.

Overall, ten protein bands were identified by peptide mass fingerprinting and database searching, viz. aminopeptidase $\mathrm{N}$ precursor (APN), lactoferrin (LF), lactoferrin isoform 1, prostatic acid phosphatase (PAP), human zinc-alpha-2-glycoprotein (hZAG), prostate specific antigen (PSA), progestagen-associated endometrial protein (PAEP), kinesin light chain 4, izumo sperm-egg fusion protein 1 (Izumo) and prolactin inducible protein (PIP) (Fig. 1B, Table 1).

The major Con A binding proteins were found to be differentially expressed in oligospermia and azoosper- mia in comparison to normospermia (Fig. 2). Overall, five proteins were downregulated in oligospermia while four proteins were downregulated and two proteins were upregulated in azoospermia. LF, PSA and PIP were found to be downregulated in both, oligospermia and azoospermia. The comparative expression analysis of identified proteins is shown in Table 2.

\section{Discussion}

Seminal plasma contains a large array of proteins involved in different steps of fertilization. These proteins are crucial for successful fertilization through various physiological events including sperm maturation, sperm movement in female reproductive tract, acrosome reaction and capacitation etc. Isolation and subsequent identification of these proteins is first step to- 
Table 2

Concanavalin A binding proteins of human seminal plasma: functions, glycosylation sites and differential expression

\begin{tabular}{|c|c|c|c|c|c|c|}
\hline \multirow[t]{2}{*}{ Protein } & \multirow[t]{2}{*}{ Functions } & \multicolumn{3}{|c|}{$\begin{array}{l}\text { Identified glycosylation sites } \\
\text { (www.expasy.ch) }\end{array}$} & \multicolumn{2}{|c|}{$\begin{array}{l}\text { Expression compared } \\
\text { to normospermia }\end{array}$} \\
\hline & & $\begin{array}{l}\text { No. of } \\
\text { sites }\end{array}$ & $\begin{array}{c}\text { Type of } \\
\text { glycosylation }\end{array}$ & $\begin{array}{l}\text { Positions in } \\
\text { sequence }\end{array}$ & Oligospermia & Azoospermia \\
\hline Aminopeptidase $\mathrm{N}$ precursor & $\begin{array}{l}\text { Proteolysis, metallopeptidase ac- } \\
\text { tivity, zinc ion binding }\end{array}$ & 6 & N-linked & $\begin{array}{l}128,234,265 \\
573,681,818\end{array}$ & No change & No change \\
\hline Lactoferrin & Iron ion transport, antimicrobial & 3 & N-linked & $156,497,642$ & Downregulated & Downregulated \\
\hline Prostatic acid phosphatase & $\begin{array}{l}\text { Catalysis, acid phosphatase acti- } \\
\text { vity }\end{array}$ & 3 & N-linked & $94,220,333$ & No change & Upregulated \\
\hline $\begin{array}{l}\text { Human } \\
\text { Zinc-Alpha-2-Glycoprotein }\end{array}$ & $\begin{array}{l}\text { Cell adhesion, immune response, } \\
\text { ribonuclease activity }\end{array}$ & 4 & N-linked & $\begin{array}{l}109,112,128 \\
259\end{array}$ & Downregulated & No change \\
\hline Prostate specific antigen & $\begin{array}{l}\text { Proteolysis, serine-type endope- } \\
\text { ptidase activity }\end{array}$ & 1 & N-linked & 69 & Downregulated & Downregulated \\
\hline $\begin{array}{l}\text { Progestagen-associated } \\
\text { endometrial protein }\end{array}$ & Transport, protein binding & \multicolumn{3}{|c|}{ Not reported } & No change & Upregulated \\
\hline Kinesin light chain 4 & $\begin{array}{l}\text { Protein binding, microtubule mo- } \\
\text { tor activity }\end{array}$ & \multicolumn{3}{|c|}{ Not reported } & No change & Downregulated \\
\hline $\begin{array}{l}\text { Izumo sperm-egg fusion pro- } \\
\text { tein } 1\end{array}$ & $\begin{array}{l}\text { Cell adhesion, fusion of sperm to } \\
\text { egg plasma membrane }\end{array}$ & 1 & N-linked & 204 & Downregulated & No change \\
\hline Prolactin inducible protein & Actin binding & 1 & N-linked & 105 & Downregulated & Downregulated \\
\hline
\end{tabular}

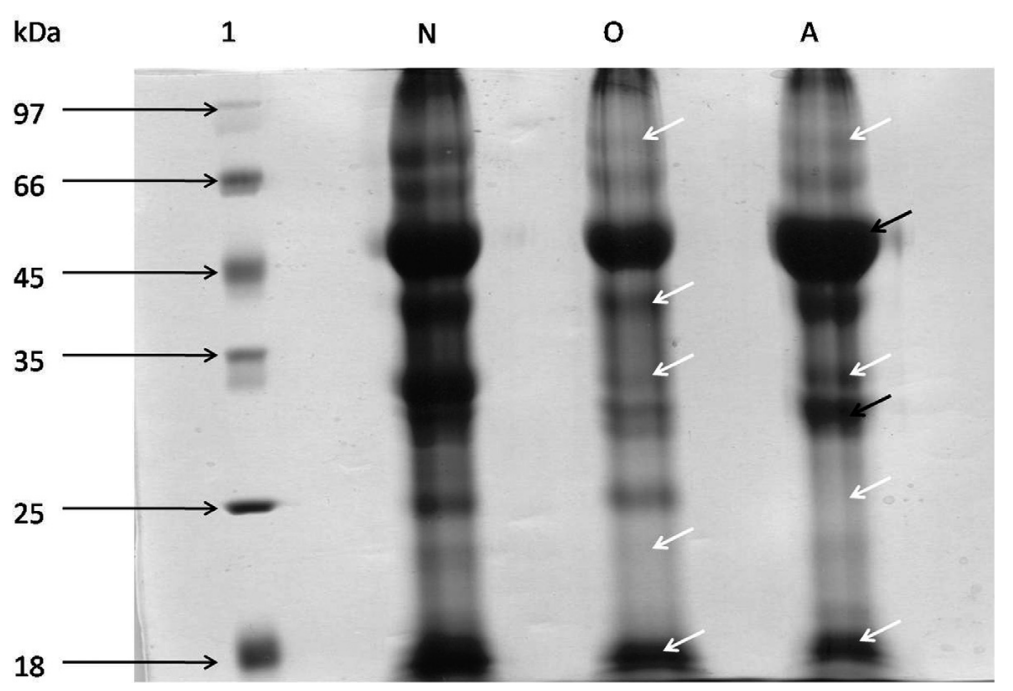

Fig. 2. Differential expression of Concanavalin A binding proteins in human seminal plasma. The fractions were analysed by $12 \%$ SDS-PAGE and protein bands were visualized by Coomassie Brilliant Blue G-250 staining. Lane 1: molecular weight markers; Lane N: Normospermic sample; Lane O: Oligospermic sample; Lane A: Azoospermic sample; Arrow representations in lanes O and A: white - downregulated protein expression, black - upregulated protein expression.

wards studying their role in fertility related processes. Glycoproteins have immense clinical importance and comparative glycoproteomics has become a powerful tool for biomarker discovery and disease diagnosis. Identification of disease-associated variations in glycosylation of peptides and proteins is the vital aim of the glycoproteomics research scientists to search more sensitive and specific diagnosis for various diseases. The glycosylation variations are directly linked to certain diseases and may be utilized as potential markers for better diagnosis and in turn, for therapeutic purposes [21]. Various individual studies have identified glycoproteins in human seminal plasma and their role in fertility/infertility related processes is also documented. Seminal plasma glycoproteins are known to participate in sperm-egg recognition [22], modulation of capacitation [23,24] and acrosome reaction inhibition [25]. It is a known fact that glycosylation modulates the physicochemical properties and conformation of the proteins, which in turn can modulate the biological activity and immunological properties. Lectins and hydrophilic affinity gels are promising tools for enrich- 
ment and isolation of glycoproteins [26,27]. Lectins which have broad specificity, such as Con A, are widely used for enriching glycoproteins these days. Con A recognizes high mannose, hybrid and biantennary complex-type N-glycans [28]. Also, Marquínez et al. had demonstrated in their research that the human seminal plasma Con A-interacting fraction shows decapacitating activity [18]. Thus, identification of Con A binding protein fraction of human seminal plasma is of paramount importance for better understanding of fertility related physiological processes. With this significant aim, we isolated Con A-binding proteins from seminal plasma, analyzed them on SDS-PAGE and subsequently identified the protein bands on gel by mass spectrometric analysis.

Overall ten Con A binding glycoproteins were identified in this study and all these proteins are known to play vital roles in various reproductive physiological processes related to fertility/infertility. The reported functions and glycosylation sites of these proteins are shown in Table 1. Preliminary studies were done to identify if there is any altered expression of Con A binding proteins. The experimental procedure was based on the fact that equal amount of sample from normospermia, oligospermia and azoospermia $(25 \mathrm{uL}$ from each) was processed in same conditions to isolate Con A binding fractions. The complete eluates from these samples were analyzed on SDS-PAGE. The difference in intensity of bands in different lanes was used to conclude the differential expression. Their differential expression in fertile and infertile samples can be justified due to the fact that their expression regulates the processes essentially required for successful fertilization. Some of these proteins are present in various molecular forms and their total expression may not be varying in fertile and infertile seminal fluid samples. This study only reports the differential expression of their gycosylated forms. PIP is a glycoprotein present in various human body fluids. It is known by various names (such as, GCDFP-15, SABP, gp17 etc.) due to its functional aspects in human reproductive and immunological systems [29]. Though the exact function of PIP is not still well understood, but its role in various biological processes such as fertility, immunoregulation, antimicrobial activity, apoptosis and tumour progression is reported. The reduced levels of PIP are also suggested to be associated with infertility [30]. Izumo belongs to the immunoglobulin superfamily and it is essentially required for sperm to fuse with eggs whose gene disruptions prevent fertility both in vitro and in vivo [31]. Kinesin is a microtubule-associated protein that plays a role in organelle transport. The suggested function of light chain is modulation of ATPase activity. PAEP has been found in the epithelium of seminal vesicles and it is secreted into the seminal plasma. It is known to have immunoregulatory activities. It was previously known as placental protein 14, progestagen-dependent endometrial protein and pregnancy-associated endometrial $\alpha 2$-globulin [32]. PSA, chymotrypsin-like protease, is a well established biomarker of prostate cancer [33]. It cleaves Semenogelin I and II (major components of human semen coagulum) rapidly after ejaculation which results in the liquefaction of the semen and release of motile spermatozoa [34]. Thus, it plays an important and essential role in the process of fertilization. It has been shown in previous studies that PSA exists in different molecular forms in human seminal plasma due to different sequence, glycosylation pattern and polypeptide length [35]. hZAG is secreted in various human body fluids and plays important functions in biological processes, including fertilization and lipid mobilization. It induces sperm forward motility in human semen [36]. PAP is a glycoprotein synthesized in the epithelial cells of the prostate gland and is secreted in high amounts into seminal fluid [37]. It has been suggested that PAP may have a physiological roles in fertility and sperm motility. LF, a member of the transferrin family of iron binding glycoproteins, is found in physiological fluids of mammals [38]. It plays an important role in immune regulation and in defense mechanisms against bacteria, fungi, parasites, and viruses. APN activity levels were found to be altered in semen from infertile patients, suggesting that this enzyme plays an important role in male fertility [39].

Despite the fact that Con A binding glycoproteins in seminal plasma are fertility related entities, proteomic profile of this fraction is very less studied. Isolation and identification of proteins in our study is an essential step towards characterization of this fraction of human seminal plasma proteome. Further characterization of these proteins, by purifying them to homogeneity, is required to establish their functional roles in fertility related process. Though, the study related to differential expression of this fraction is in preliminary stage but of considerable importance as it enumerates that the proteins in this fraction are differentially expressed in fertile and infertile seminal plasma. To further identify and characterize the differential expression, the purification of proteins of interest is under process. Once proteins are purified, we will study the nature of differential expression using western blotting and identification of attached glycans. Thus, this study may serve as 
a new reference point to guide future studies towards identification of male infertility marker proteins in human seminal plasma.

\section{Acknowledgement}

This work is supported by research grant from Department of Science \& Technology (DST), Government of India, New Delhi. Anil Kumar Tomar also thanks DST for his fellowship. Authors also thank Mayank Saraswat (Centre for Bioanalytical Sciences, School of Biotechnology, Dublin City University, Dublin) for his critical suggestions and Sushila Yadav (Department of Biophysics, All India Institute of Medical Sciences, New Delhi) for her help during experiments.

\section{References}

[1] P.J. Turek, Practical approaches to the diagnosis and management of male infertility, Nat Clin Pract Urol 2 (2005), 226238.

[2] K.L. Pixton, E.D. Deeks, F.M. Flesch, F.L. Moseley, L. Bjorndahl, P.R. Ashton, C.L. Barratt and I.A. Brewis, Sperm proteome mapping of a patient who experienced failed fertilization at IVF reveals altered expression of at least 20 proteins compared with fertile donors: case report, Hum Reprod 19 (2004), 1438-1447.

[3] B. Pilch and M. Mann, Large-scale and high-confidence proteomic analysis of human seminal plasma, Genome Biol 7 (2006), R40

[4] C. Zhao, R. Huo, F.Q. Wang, M. Lin, Z.M. Zhou and J.H. Sha, Identification of several proteins involved in regulation of sperm motility by proteomic analysis, Fertil Steril 87 (2007), 436-438.

[5] J. Martinez-Heredia, S. de Mateo, J.M. Vidal-Taboada, J.L. Ballescà and R. Oliva, Identification of proteomic differences in asthenozoospermic sperm samples, Hum Reprod 23 (2008), 783-791.

[6] T.T. Liao, Z. Xiang, W.B. Zhu and L.Q. Fan, Proteome analysis of round-headed and normal spermatozoa by 2-D fluorescence difference gel electrophoresis and mass spectrometry, Asian J Androl 11 (2009), 683-693.

[7] F. Secciani, L. Bianchi, L. Ermini, R. Cianti, A. Armini, G.B. La Sala, R. Focarelli, L. Bini and F. Rosati, Protein Profile of Capacitated versus Ejaculated Human Sperm, J Proteome Res 8 (2009), 3377-3389.

[8] A.B. Siva, D.B. Kameshwari, V. Singh, K. Pavani, C.S. Sundaram, N. Rangaraj, M. Deenadayal and S. Shivaji, Proteomics-based study on asthenozoospermia: differential expression of proteasome alpha complex, Mol Hum Reprod 16 (2010), 452-462.

[9] M.A. Baker, G. Reeves, L. Hetherington and R.J. Aitken, Analysis of proteomic changes associated with sperm capacitation through the combined use of IPG-strip pre-fractionation followed by RP chromatography LC-MS/MS analysis, Proteomics 10 (2010), 482-495.
[10] K. Yamakawa, K. Yoshida, H. Nishikawa, T. Kato and T. Iwamoto, Comparative analysis of interindividual variations in the seminal plasma proteome of fertile men with identification of potential markers for azoospermia in infertile patients, $J$ Androl 28 (2007), 858-865.

[11] J. Bai, S.H. Fu, L.L. Cai, L. Sun and Y.L. Cong, Identification of differential proteins in the seminal plasma of healthy fertile and non-obstructive azoospermia men by shotgun proteomic strategy, Zhonghua Nan Ke Xие 16 (2010), 887-896.

[12] X. Wei and L. Li, Comparative glycoproteomics: approaches and applications, Brief Funct Genomic Proteomic 8 (2009), 104-113.

[13] M.V. Novotny and Y. Mechref, New hyphenated methodologies in high-sensitivity glycoprotein analysis, J Sep Sci 28 (2005), 1956-1968.

[14] S. Ogata, T. Muramatsu and A. Kobata, Fractionation of glycopeptides by affinity column chromatography on concanavalin A-sepharose, J Biochem 78 (1975), 687-696.

[15] C.F. Brewer and L. Bhattacharyya, Specificity of concanavalin A binding to asparagine-linked glycopeptides. A nuclear magnetic relaxation dispersion study, J Biol Chem 261 (1986), 7306-7310.

[16] R.G. Spiro, Glucose residues as key determinants in the biosynthesis and quality control of glycoproteins with $\mathrm{N}$ linked oligosaccharides, J Biol Chem 275 (2000), 3565735660 .

[17] J.B. Owen, F. Di Domenico, R. Sultana, M. Perluigi, C. Cini, W.M. Pierce and D.A. Butterfield, Proteomics-determined differences in the concanavalin-A-fractionated proteome of hippocampus and inferior parietal lobule in subjects with Alzheimer's disease and mild cognitive impairment: implications for progression of AD, J Proteome Res 8 (2009), 471482.

[18] A.C. Marquínez, A.M. Andreetta, N. González, C. Wolfenstein-Todel and J.M. Scacciati de Cerezo, Identification of gp17 glycoprotein and characterization of prostatic acid phosphatase (PAP) and carboxypeptidase E (CPE) fragments in a human seminal plasma fraction interacting with concanavalin A, J Protein Chem 22 (2003), 423-429.

[19] U.K. Laemmli, Cleavage of structural proteins during the assembly of the head of bacteriophage T4, Nature 227 (1970), 680-685.

[20] M. Alam, M. Selladurai, S. Nagpal, A.K. Tomar, M. Saraswat, M. Raziuddin, S. Mittal, T.P. Singh and S. Yadav, Sample complexity reduction aids efficient detection of low-abundant proteins from human amniotic fluid, J Sep Sci 33 (2010), 1723-1729.

[21] G. Durand and N. Seta, Protein glycosylation and diseases: Blood and urinary oligosaccharides as markers for diagnosis and therapeutic monitoring, Clin Chem 46 (2000), 795-805.

[22] A. Iborra, C. Morte, P. Fuentes, V. García-Framis, P. Andolz and P. Martínez, Human sperm coating antigen from seminal plasma origin, Am J Reprod Immunol 36 (1996), 118-125.

[23] I. Thérien, G. Bleau and P. Manjunath, Phosphatidylcholinebinding proteins of bovine seminal plasma modulate capacitation of spermatozoa by heparin, Biol Reprod 52 (1995), 1372-1379.

[24] J.J. Calvete, E. Carrera, L. Sanz and E. Töpfer-Petersen, Boar spermadhesins AQN-1 and AQN-3: oligosaccharide and zona pellucida binding characteristics, Biol Chem 377 (1996), 521527.

[25] R.C. Drisdel, S.R. Mack, R.A. Anderson and L.J. Zaneveld, Purification and partial characterization of acrosome reaction 
inhibiting glycoprotein from human seminal plasma, Biol Reprod 53 (1995), 201-208.

[26] N. Sharon, Lectins: past, present and future, Biochem Soc Trans 36 (2008), 1457-1460.

[27] M. Tajiri, S. Yoshida and Y. Wada, Differential analysis of site-specific glycans on plasma and cellular fibronectins: application of a hydrophilic affinity method for glycopeptide enrichment, Glycobiology 15 (2005), 1332-1340.

[28] M. Madera, B. Mann, Y. Mechref and M.V. Novotny, Efficacy of glycoprotein enrichment by microscale lectin affinity chromatography, J Sep Sci 31 (2008), 2722-2732.

[29] M.I. Hassan, A. Waheed, S. Yadav, T.P. Singh and F. Ahmad, Prolactin inducible protein in cancer, fertility and immunoregulation: structure, function and its clinical implications, Cell Mol Life Sci 66 (2009), 447-459.

[30] R.A. Bronson, Antisperm antibodies: a critical evaluation and clinical guidelines, J Reprod Immunol 45 (1999), 159-183.

[31] N. Inoue, M. Ikawa, A. Isotani and M. Okabe, The immunoglobulin superfamily protein Izumo is required for sperm to fuse with eggs, Nature 434 (2005), 234-238.

[32] M. Julkunen, T. Wahlstrom, M. Seppala, R. Koistinen, A. Koskimies, U.H. Stenman and H. Bohn, Detection and localization of placental protein 14-like protein in human seminal plasma and in the male genital tract, Arch Androl 12 (1985), 59-67.

[33] J.E. Oesterling, Prostate specific antigen: a critical assessment of the most useful tumor marker for adenocarcinoma of the prostate, J Urol 145 (1991), 907-923.

[34] H. Lilja, A kallikrein-like serine protease in prostatic fluid cleaves the predominant seminal vesicle protein, J Clin Invest 76 (1985), 1899-1903.

[35] V. Kumar, M.I. Hassan, A.K. Singh, S. Dey, T.P. Singh and S. Yadav, Strategy for sensitive and specific detection of molecular forms of PSA based on 2DE and kinetic analysis: a step towards diagnosis of prostate cancer, Clin Chim Acta $\mathbf{4 0 3}$ (2009), 17-22.

[36] Z. Ding, F. Qu, W. Guo, X. Ying, M. Wu and Y. Zhang, Identification of sperm forward motility-related proteins in human seminal plasma, Mol Reprod Dev 74 (2007), 11241131.

[37] L. Hakalahti, P. Vihko, P. Henttu, H. Autio-Harmainen, Y. Soini and R. Vihko, Evaluation of PAP and PSA gene expression in prostatic hyperplasia and prostatic carcinoma using northern-blot analyses, in situ hybridization and immunohistochemical stainings with monoclonal and bispecific antibodies, Int J Cancer 55 (1993), 590-597.

[38] M.H. Metz-Boutigue, J. Jollès, J. Mazurier, F. Schoentgen, D. Legrand, G. Spik, J. Montreuil and P. Jollès, Human lactotransferrin: amino acid sequence and structural comparisons with other transferrins, Eur J Biochem 145 (1984), 659-676.

[39] J. Irazusta, A. Valdivia, D. Fernández, E. Agirregoitia, C. Ochoa and L. Casis, Enkephalin-degrading enzymes in normal and subfertile human semen, J Androl 25 (2004), 733-739. 


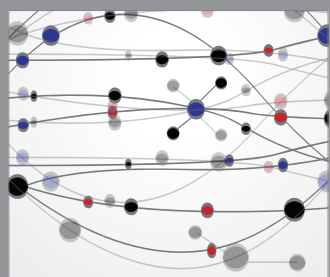

The Scientific World Journal
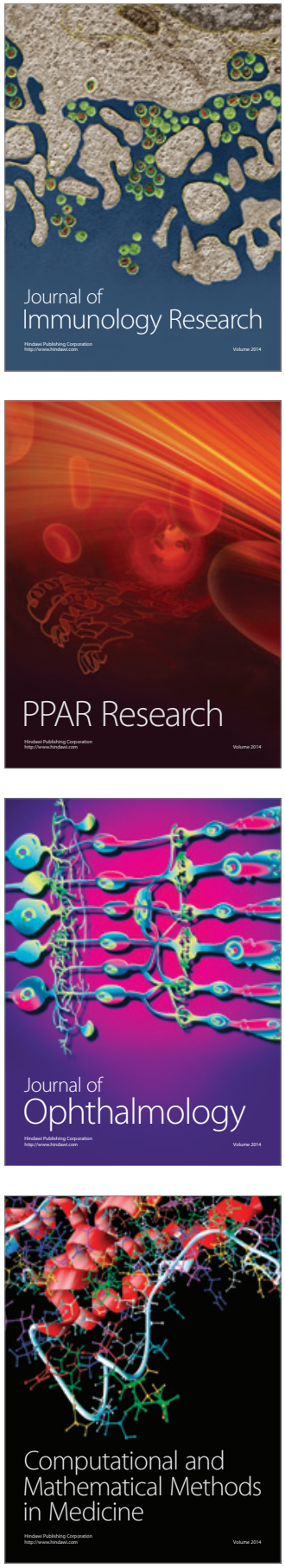

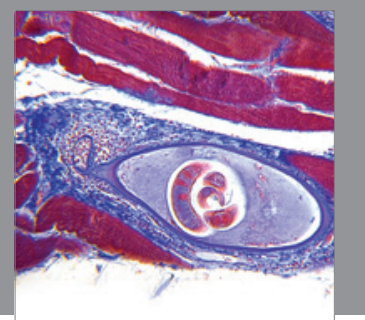

Gastroenterology

Research and Practice
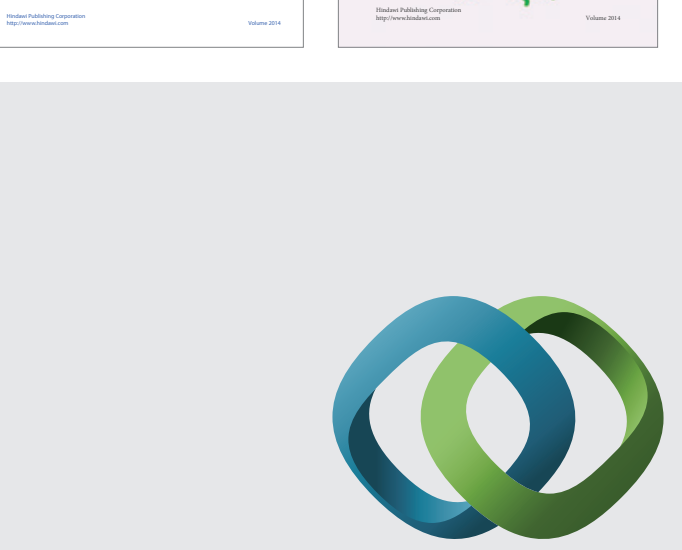

\section{Hindawi}

Submit your manuscripts at

http://www.hindawi.com
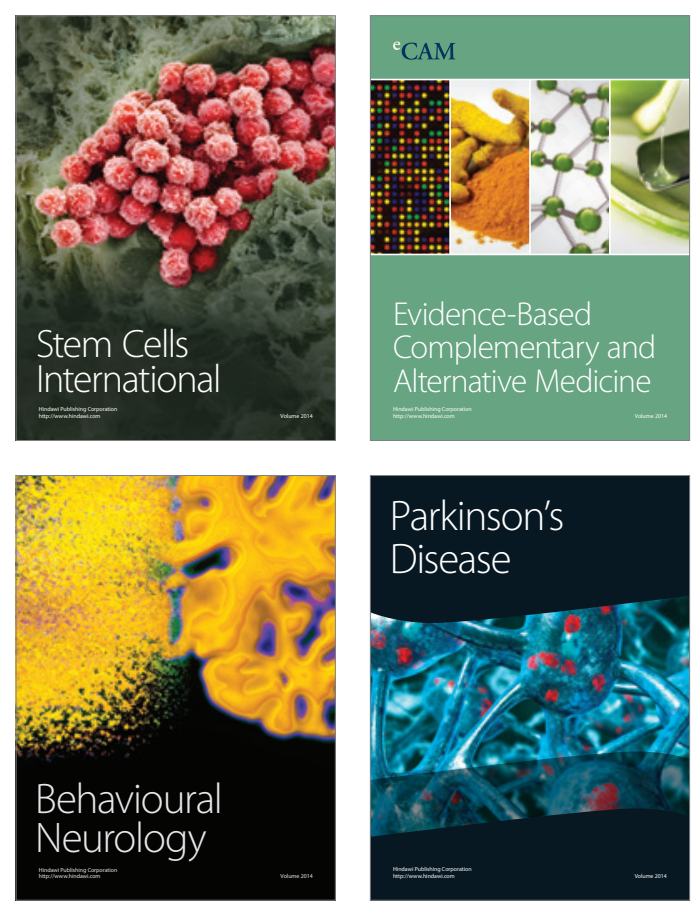

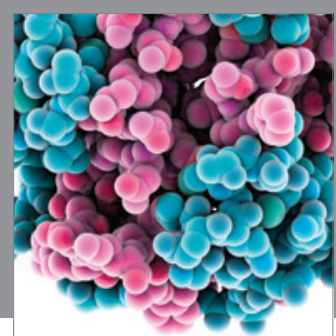

Journal of
Diabetes Research

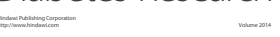

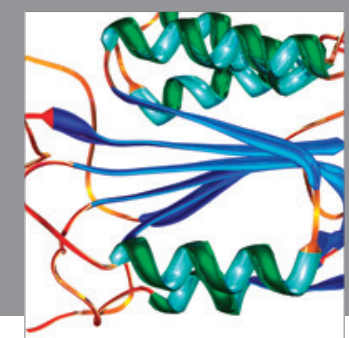

Disease Markers
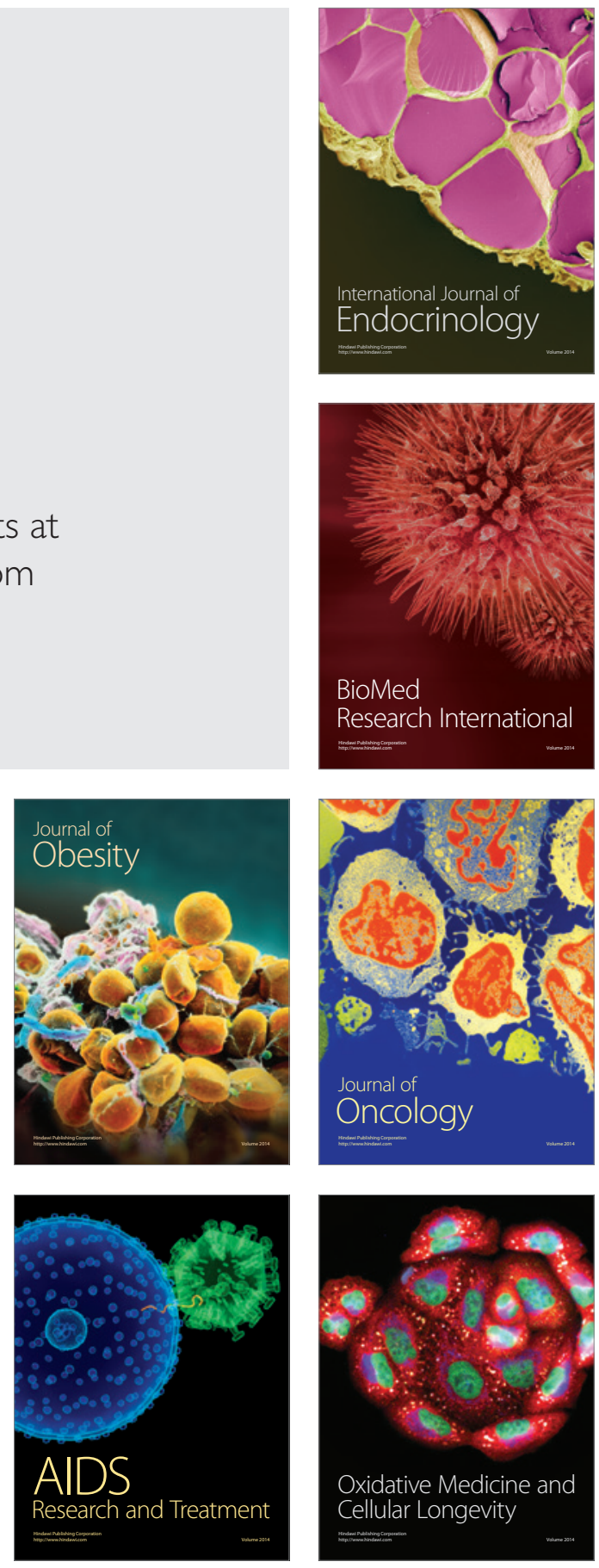